\title{
LA INTERPRETACIÓN EN ARQUEOLOGÍA, PASOS HACIA LA HERMENEUTICA DEL REGISTRO
}

\author{
The Interpretation in Archaeology,
}

Steps towards the Record Hermeneutics

JuAn PABlo CARbonelli

(Museo Etnográfico/CONICET, Argentina)

\begin{abstract}
Resumen
En este trabajo abordaremos la asociación entre arqueología y hermenéutica. Para ello, en primer lugar, efectuaremos un breve recorrido sobre los cuerpos teóricos que existen en arqueología. A continuación, deconstruiremos la aplicación del falsacionismo en la disciplina, y a través de dicha crítica trasladaremos su objeto de estudio al escenario post-empirista de las ciencias sociales. Esto dará lugar a la comparación entre el registro arqueológico y el texto, y como resultado, la incorporación de horizontes de subjetividad a la interpretación arqueológica.
\end{abstract}

Palabras clave: Arqueología | Hermeneútica | Ciencias Sociales | Interpretación

\begin{abstract}
This paper will address the association between archaeology and hermeneutics. For this purpose, first, we will make a brief tour on existing theoretical bodies in archaeology. Then we deconstruct the application of falsifiability in the discipline, and through this critique we will move its subject to the post-empiricist stage of social science. This will lead to the comparison between the archaeological record and the text, and as a result, the addition of subjectivity horizons to archaeological interpretation.
\end{abstract}

Keywords: Archaeology | Hermeneutics | Social Sciences | Interpretation 


\section{Introducción}

En este trabajo intentaremos dar cuenta de cuál ha sido el modelo de ciencia que ha guiado la explicación en arqueología. En primer lugar, abordaremos la epistemología del enfoque teórico procesual, que generó las primeras explicaciones hipóteticas-deductivas en la disciplina. En segundo lugar, indagaremos sobre las falencias de la aplicación del modelo hipótetico-deductivo en las ciencias sociales en general, y en la arqueología en particular. Finalmente, y a manera de propuesta, continuaremos con la vía epistemológica y teórica que acerca la hermeneútica y la arqueología (Hodder, 1986, 1987, Preucel y Hodder, 1996). A continuación exploraremos las simili-tudes entre la acción y el texto (Ricoeur, 2008 [1985]), y de qué forma podemos trasladar dichas semejanzas al registro arqueológico.

\section{La arqueología y el modelo de las ciencias naturales}

Consideramos que la ciencia arqueológica ha transitado por tres períodos de hegemonía teórica, y que cada uno de ellos ha definido su relación con su objeto de estudio (el artefacto / el pasado del hombre).

En primer término, la denominada Escuela Histórico Cultural. En dicho marco teórico el objetivo disciplinar radicaba en ordenar una sucesión de hechos en el tiempo. Utilizando una metáfora, podríamos decir que su meta como teoría era ordenar en estantes distintas culturas. Ontológicamente esencialista, la Escuela Histórico Cultural nace en Europa central y septentrional, a mediados del siglo XIX como una consecuencia del nacionalismo y del romanticismo (Trigger, 1989). Esto condujo a los arqueólogos a

preocuparse por los problemas históricos y étnicos, y a denominar las culturas y civilizaciones como “...conjuntos de material arqueológico prehistórico y geográfica y temporalmente restringidos y su identificación como los restos de diversos grupos étnicos..." (Trigger, 1989:157).

Para este marco teórico, las culturas eran definidas como estáticas por naturaleza y la variabilidad en el registro arqueológico era explicada a través de procesos como la difusión y la migración. De esta forma, se consideraba a la cultura como una forma de vida transmitida por pueblos específicos de generación en generación; 
comparativamente, pode-mos hablar de un conjunto cerrado de rasgos que permitía identificar una etnia en el registro arqueológico.

Epistemológicamente, la Escuela Histórico Cultural llevaba a cabo un enfoque inductivista: a través de lo observado y analizado en el trabajo de campo, reunía y completaba, lentamente los aspectos de la cultura estudiada. Por lo tanto, la interpretación del pasado se construía como un rompecabezas, donde cada dato representaba una pieza del total de la cultura.

En 1960, se produce en la disciplina la irrupción de un nuevo enfoque hegemónico: la Nueva Arqueología, que tuvo sus orígenes en el funcionalismo y en el neo-evolucionismo. De dichas corrientes fue de donde surgió una nueva definición de cultura: como un medio extrasomático de adaptación al medio ambiente. Con respecto al modelo teórico anterior, ahora el objetivo de la arqueología se emparentaba con el de la antropología: explicar las diferencias y similitudes del comportamiento cultural (Trigger, 1989).

A través de la arqueología procesual, se ubicó a la disciplina arqueológica dentro del modelo de las ciencias naturales, en su búsqueda de generalizaciones empíricas. El rechazo al método de las ciencias sociales radicaba en que "...[los arqueólogos] no observan hechos sociales; observan hechos materiales, todos ellos contemporáneos, y, por tanto, los procedimientos de las ciencias sociales en la práctica son inapropiados para la arqueo-logía..." (Binford, 1988:25).

Es, de esta manera, la materialidad la que une la arqueología al modelo empirista de las ciencias naturales. Otra noción que se desprende de la cita anterior, es que el registro arqueológico es un fenómeno contemporáneo (Ebert y Kohler, 1988).

Hodder (1987) amplía esta descripción en su explicación acerca del rechazo de por parte de la "Nueva Arqueología" de la interpretación de los significados simbólicos. Este autor describe que los Nuevos Arqueólogos incorporaron el modelo de las ciencias naturales para ser reconocidos como científicos, rigurosos y objetivos y en definitiva, ser aceptados por el resto de la comunidad científica. Adoptaron entonces una versión del positivismo: el método hipótetico-deductivo de Hempel. Esto implicaba deducir implicaciones a partir de teorías generales, y ponerlas a pruebas con datos independientes (Binford, 1981).

Desde sus principios, la Nueva Arqueología comprendió que sólo mediante el estudio de situaciones vivientes, donde pudiera observarse el comportamiento y las ideas en conjunción con la cultura material, podrían establecer correlaciones a través de las cuales inferir el comportamiento social que se materializaba en el registro arqueológico. En otras palabras, la regularidad del comportamiento humano podría ser relevada a través de estudios etnográficos comparativos. Metodológicamente, en primer lugar el arqueólogo debía aislar los diferentes agentes o fuerzas que generaron un determinado patrón. Y en 
segundo lugar, estudiar dichos agentes o procesos en el mundo contemporáneo, buscando especificar criterios para reconocer los patrones que se han preservado en el registro arqueológico (Binford, 1981).

Dichos estudios actualísticos eran aplicados para establecer una conexión entre las propiedades dinámicas de las conductas del pasado (que el arqueólogo deseaba conocer) y las propiedades materiales estáticas comunes entre el pasado y el presente. Esta clase de estudio fueron denominados como Teorías de Rango Medio (Binford, 1977) y contribuían a la generación de hipótesis empíricas falsables, como respuestas a la teoría general (Ebert y Kohler, 1988). Debemos destacar aquí, la creencia que existía en la Nueva Arqueología sobre la existencia de leyes en la naturaleza, que explicasen la conducta humana del pasado. En resumen, la explicación en arqueología implicaba integrar los datos arqueológicos con otro tipo de información (etnográfica, etnoarqueológica, histórica, ambiental) para crear modelos que conecten el registro arqueológico con lo que sucedió en el pasado (Ebert y Kohler, 1988).

\section{La falsación y las ciencias sociales}

En este apartado expondremos una serie de críticas a la aplicación del falsacionismo, para las ciencias sociales en general y para la arqueología en particular. Una finalidad concreta de dicha crítica es incorporar epistemológicamente la arqueología al terreno de las ciencias sociales, donde lentamente se ha abandonado el método hipotético deductivo.

En primer lugar, para introducirnos en la discusión, consideramos necesario marcar que Popper (1981a) distingue tres contextos dentro de la investigación científica: el de descubrimiento de una ley, el de justificación de la misma y el de aplicación. Para Popper (1981a) el método científico se encontraba atado al contexto de justificación, denominando historicismo a cualquier otra interpretación que tuviera una dependencia histórica. Según los analistas de su obra, la unidad de las ciencias se fundaba en el criterio de falsabilidad estricta (Hidalgo, 2004). Este era un parámetro al que, como marcamos anteriormente, deseaban llegar los arqueólogos post-positivistas.

Una de las críticas que podemos realizar a la aplicación del modelo hipotético-deductivo a la arqueología, es el presupuesto que en el proceso de constrastación intersubjetiva, desar-rollado en el contexto de justificación, la objetividad descansa unívocamente en el objeto. En otras palabras, siguiendo el análisis de Fernando García (2004), es dable pensar que para Popper la ciencia consiste únicamente en el método, en una lógica de la 
investigación, haciéndose abstracción de su objeto. A través del falsacionismo, es factible relativizar el proceso de observación de la experiencia con respecto al resultado de la confrontación crítica de las teorías (Hoyos Vazquez 2004). Esta relativización, conlleva la posición de sostener la completa autonomía del objeto arqueológico (artefacto) respecto al sujeto cognoscente (Carbonelli, 2011).

En contraposición a esto último, sostenemos que en cada contrastación, falsando una hipótesis, también se ponen en juego términos teóricos. Estos se encuentran indisolublemente ligados a la experiencia y a los términos observacionales (Feyerabend, 1981). En Arqueología es ficticia toda separación entre metodología y teoría, en particular al momento de integrar las distintas líneas de evidencia (tecnología lítica, cerámica, patrones de asentamiento, subsistencia, simbo-lismo) y darles sentido. Las elecciones técnicas más empíricas a la hora de decidir como excavar, delimitar un sitio y sus componentes son inseparables de las elecciones teóricas de construcción del objeto (Carbonelli y Gamarra, 2011).

En dicho sentido, consideramos que la arqueología, como el resto de las ciencias sociales, a diferencia de las ciencias naturales (quienes analizan objetos independientes de toda conciencia y significación), son las que van construyendo su objeto científico, de acuerdo a su propia tradición y a las singularidades propias del contexto socio-histórico que atraviesan. En Ciencias Sociales, las teorías no sólo se utilizan para elaborar leyes para ser contrastadas, sino también para construir el concepto de aquello sobre lo que se hace ciencia (Fernando García, 2004). Como consecuencia, el falsacionismo no resulta un criterio adecuado para determinar la verdad y la falsedad de los enunciados de las ciencias sociales. Prueba de ello, es el hecho que

... las leyes de la vida social son leyes de las acciones de los hombres, que no son exteriores a ellas, y por lo tanto, no pueden dejarse de manifestarse a través de dichas acciones, de ser mediaciones... (Fernando García, 2004:259).

En el caso concreto de la arqueología, las leyes de la vida social que se busca contrastar en el registro arqueológico, se hallan mediatizadas por las elecciones teóricas de los investigado-res: las consecuencias observacionales de toda teoría importada por la arqueología se hallan impregnadas de conceptos abstractos y metafísicos. A manera de ejemplo podemos citar como son conceptualizadas las sociedades del noroeste argentino, durante los siglos anteriores a la llegada del imperio Inkaico: ya sea como jefaturas, donde reina la estratificación económica, la desigualdad social y el acceso diferencial a los recursos (Tarragó, 2000; Nielsen 2001); o como sociedades inmersas en la integración comunal y la homogeneidad material y simbólica (Acuto, 2007). Cada una 
de estas visiones construye los indicadores arqueológicos necesarios para dar cuenta de esa realidad. Para decirlo en otras palabras, cada postura teórica coloca un prisma sobre el investigador que efectivamente produce un contexto de justificación que no es inocuo, sino que por el contrario, las consecuencias observaciones son producidas por la teoría y la retroalimentan.

En consonancia a esto último, como sostiene Lores Arnaiz (2004) el criterio falsacionista lleva implícito la confianza de Popper y los positivistas críticos en la autorregulación de la ciencia. Acerca de esto último, consideramos que es una percepción ingenua del propio quehacer científico. Es innegable el peso de las condiciones socio-históricas sobre la elaboración de hipótesis (por que surgen determinadas ideas o preguntas en un contexto y por qué no en otro) y fundamentalmente, en su validación y perpetuidad. Dentro de las ciencias sociales, el poder de determinadas escuelas de pensamiento asociadas al poder político legitima la producción científica elaborada en el campo. En la Arqueología Argentina, por ejemplo, la propagación de las ideas difusionistas de la Escuela de Viena, estuvieron atadas (desde 1930 a 1950) a su amistad con el poder político nacional. En relación a esto, Popper (1981b:419) establecía que las conexiones entre la razón y las circunstancias socio-histórica “...contie-nen una verdad innegable, pero trivial...".

La resistencia que existe en Arqueología, en efectuar un acercamiento interpretativo a los datos, podemos rastrearlo en la propia concepción de Popper sobre las ciencias sociales y la historia. Dicho autor rechazaba como no científico a todas las interpretaciones de situaciones históricas y a la atribución a la historia de algún significado (Hidalgo, 2004). Por consiguiente "la única salida para las ciencias sociales es olvidar todos los artificios verbales y encarar los problemas prácticos de nuestro tiempo, con la ayuda de los modelos teóricos, que en esencia, son los mismos en todas las ciencias..." (Popper, 1977: 243).

El rigor científico de Popper (1977) señalaba que no podían existir leyes en la historia, pues ésta era un proceso rico de hechos singulares, en el cual era difícil establecer regularidades, explicaciones y predicciones. Aplicando en sentido estricto el criterio falsacionista, la arqueología durante la década del 60 intentó alejarse de esta postura desdeñada por el falsacionismo, buscando en el registro arqueológico poder establecer generalizaciones empíricas de la conducta humana. Uno de sus intentos fue la etnoarqueología: el análisis de situaciones vivientes para deducir patrones del registro arqueológico. Sin embargo, consideramos que frecuentemente se cayó en el riesgo de asumir como leyes trans-culturales hipótesis elaboradas en un contexto específico. Por el contrario, sugerimos que el análisis de una sociedad del pasado deber ser contextualizado históricamente e interpretada individualmente. 
A continuación en el siguiente apartado, enumeraremos las condiciones para que el registro arqueológico pueda ser interpretado, ingresando al mundo de la hermeneútica (el tercer marco teórico hegemónico).

\section{Epistemología y Hermeneútica}

Siguiendo a Johnsen y Olsen (1992) sostenemos que uno de los aportes que puede brindarle la hermeneútica a la arqueológia es cuestionarse sobre cuáles son las precondiciones necesarias para poder comprender el pasado. Lamentablemente, dicha pregunta fue dejada de lado por la disciplina, en su afán por eliminar todos los prejuicios y métodos subjetivos. No obstante, si aceptamos a la arqueología como una ciencia social, consideramos que esta disciplina no puede escapar de la doble hermeneútica (Guiddens, 1987) inherente a todo objeto de estudio construído socialmente. Profundizando dicha acepción, el mismo Guiddens (1987:357) había señalado las coincidencias entre la arqueología y la hermeneútica:

...If there are two disciplines, the, whose intersection concerns the limits of presence, they are surely those of archaeology and hermeneutics: archaeology because this is the subject par excellence wich is concerned with relics o remains (...) hermeneutics, because all survivals of a conserved past have to be interpreted... (Guiddens, 1987:357)

Para poder aplicar un acercamiento hermeneútico a la arqueología, sugerimos imprescindible diferenciar dos tipos de significados del objeto arqueológico (Hodder, 1986): en primer término, el significado funcional sujeto a las cualidades intrínsecas como material. En dicho sentido, el significado del objeto se desarrolla a partir de su relación con otros factores y procesos, en relación con las estructuras sociales y económicas.

Y en segundo lugar, el significado que contiene los símbolos e ideas. Para poder acceder a este tipo de significado debemos de tener en cuenta que, como intérpretes accedemos al pasado con todos nuestros paquetes de prejuicios. Porque comprender es una relación histórica (Gadamer, 1975), sujeta a la tradición de las investigaciones y a nuestra propia biografía. De esta forma, superamos la añeja desvinculación entre el sujeto cognoscente y el objeto sobre el cual predicamos (como sostiene la epistemología procesual): nosotros interpretamos un pasado que no se encuentra divorciado de nosotros, sino activamente involucrado en nuestra comprensión (Johnsen y Olsen, 1992:430). 


\subsection{Rasgos inherentes de la Acción-Texto-Objeto arqueológico}

En el segundo significado del objeto, encontramos una pista sobre el puente que une el procedimiento del arqueólogo al indagar en su registro y la labor del hermeneuta. Si el objeto es un símbolo, podemos empezar a considerar a todo el registro arqueológico como un texto. De esta forma, podemos efectuar un aporte a la pregunta de Ricoeur (2008:57): ¿Hasta qué punto podemos decir que el objeto de las ciencias humanas se ajusta al paradigma del texto? Ricoeur (2008) responde a esta formulación a través de 4 rasgos principales que marcan e igualan la objetivación del texto y de la acción: a) la fijación del significado, b) su disociación de la intención mental del autor, c) la exhibición de referencias no ostensivas; d) el abanico universal de sus destinatarios. A continuación discutiremos la aplicación de estas cualidades al objeto arqueológico, producto de las acciones pasadas del hombre.

En referencia al primer rasgo, la fijación del significado, Ricoeur (2008:64) menciona que de la misma forma que el discurso se objetiva al materializarse en la escritura (exteriorizándose de la intención del autor), el significado de la acción se objetiva al desprenderse del acontecimiento. Trasladando esta situación a la arqueología, podemos decir que el acontecimiento se halla encerrado en el objeto arqueológico, en el artefacto. El acontecimiento es la situación que se desarrolló en un instante en la historia de la humanidad, de la que únicamente nos queda su testimonio físico. No obstante, el significado de dicho acto se disocia del pasado y es retomado por el arqueólogo.

Concatenado al primer rasgo, Ricoeur (2008) afirma que de la misma forma que un texto se desprende su autor (y es releído e interpretado por múltiples actores), la acción se desprende de su agente y desarrolla sus propias consecuencias. Ricoeur (2008) también llama a este rasgo como la autonomización social de la acción. Sugerimos que en arqueología, si podemos hacer de una punta de proyectil objeto de nuestra investigación, es porque el significado de la acción del pasado (de la cual la punta fue un vehículo) se objetiva y se desarrolla en forma autónoma a las intenciones de los autores/protagonistas originales. Esta autonomización constituye la dimensión social de la acción y nos permite que se convierta en nuestro objeto científico. Toda acción (presente o pasada) deja una huella, una señal. La historia misma es un continuo registro de la acción (Ricoeur, 2008). Las acciones del pasado quedaron materializadas (i.e., en los desechos de talla, en los muros, en los pukaras, en la decoración cerámica), inscriptas socialmente y, por lo tanto, se constituyen como archivos y se van sedimentando en el tiempo social, institucionalizándose y separándose definitivamente de la intención primigenia. Esta última acepción nos ayuda a concebir al registro arqueológico como un documento; 
testimonio de un acontecimiento de la prehistoria, pero también como un espacio independiente, que existe en nuestro presente.

Finalmente, siguiendo la comparación efectuada entre el texto y la acción y aplicándola al objeto arqueológico, uniremos el concepto del tercer y cuarto rasgo. Ricoeur (2008) menciona que al igual que un texto, la acción humana excede, sobrepasa y trasciende las condiciones sociales de su producción; quedando su significado en suspenso, sujeto a nuevas interpretaciones. De la misma forma, se suceden en Arqueología múltiples explicaciones sobre un mismo acontecimiento, por ejemplo la relaciones entre el Imperio Inkaico y las sociedades del NOA durante los siglos XV y XVI: ¿fueron del todo asimétricas?, ¿hubo resistencia?, ¿existió dominación simbólica y efectiva?, ¿el tributo fue parte de una estrategia o un intercambio pacífico? De más está decir que el significado del contacto entre dos pueblos, sobrepasa las dimensiones del acontecimiento histórico, y es representado constantemente y nuevamente en otros contextos sociales, como el de la comunidad académica.

Consideramos que los cuatro rasgos exhibidos anteriormente, nos ayudan a comprender la asociación entre el registro arqueológico (conformado por acciones llevadas a cabo en el pasado) y el texto. Esto crea un espacio propicio para la Hermeneútica, para empezar a utilizar las reglas requeridas para la interpretación de los documentos / registro = escritos / materializados. En la siguiente sección, abordaremos como llevar a cabo dicha metodología.

\subsection{Metodología de enlace entre la arqueología y la hermeneútica}

Sin lugar a dudas, una propuesta que interpela el entrelazamiento entre la arqueología y la hermeneútica, se enfrenta a la siguiente paradoja: de la misma manera que el positivismo y el modelo hipotético-deductivo no dan cuenta de la dimensión subjetiva de lo real, el método hermeneútico puede no dar cuenta las dimensiones objetivas de lo humano, de las bases reales de la cultura (Criado Boado, 2006).

Una de las vías metodológicas para solucionar dicha paradoja es la propuesta por Criado Boado (2006), donde dicho autor insta a producir interpretaciones objetivadas $u$ objetivables. Esto se efectuaría mediante el Método Interpretativo (asumiendo todas las contradicciones que dicho concepto encierra), el cual consta de dos fases: la primera de enunciación de las interpretaciones y la segunda de interpretación de las interpretaciones. En la primera fase se generan hipótesis interpretativas, poniendo a prueba su coherencia interna y validez. En este paso, el arqueólogo debe buscar la recurrencia estructural (sin la necesidad de establecer explicaciones de origen causal), y 
establecer si el enunciado interpretativo se corresponde con lo real, si es factible hallar un patrón.

En el segundo paso, se incorporan horizontes de subjetividad diferentes sobre los cuales contextualizar la interpretación arqueológica (Criado Boado, 2006). Según Criado Boado (2006) se trata de comprender e interpretar los enunciados hipotéticos generados en el primer paso. Dicha interpretación se efectúa dentro del propio horizonte de subjetividad del fenómeno estudiado, incorporando modelos del saber antropológico, sociológico, de las ciencias políticas, de la lingüística, etc. El significado se introduce aquí no desde la propia subjetividad del intérprete, sino mediante un modelo contextual, que al incorporar cuerpos teóricos distintos otorga sentido a la interpretación generada en el primer paso.

En la metodología propuesta por Criado Boado (2006) encontramos semejanzas con la dialéctica entre explicación y comprensión propuesta por Ricoeur (2008), para las Ciencias Sociales. Cuando intentamos explicar el registro arqueológico, lo que Boado (2006) denomina formular hipótesis interpretativas, exponemos nuestra interpretación al juicio y a la competencia con otras interpretaciones rivales. Como bien lo ha establecido Ricoeur (2008), pertenece al quehacer propio de las ciencias humanas el reconocer la plurivocalidad del significado de la acción humana. Entonces, la validación aquí, es llevada a cabo por el conflicto y la tensión entre interpretaciones. A raíz de esto, difiere de la verificación empírica, ya que “...sostener que una inter-pretación es más probable que otra, es algo diferente a mostrar que una conclusión es verdadera..." (Ricoeur, 2008: 74). A diferencia del falsacionismo, en este caso la verdad no descansa en la experiencia, sino en la argumentación, en el plano teórico. La objetividad se obtiene a través de la convalidación y competencia de las opiniones previas, en su proceso de formulación (Gadamer, 1975). Esto reestablece el vínculo entre el sujeto cognoscente y el objeto arqueológico, porque el investigador se involucra plenamente en su argumentación.

Al situarnos en el trayecto que va de la explicación a la comprensión, el segundo paso propuesto por Boado (2006), podemos establecer un nexo con el concepto de fusión de horizontes de Gadamer (1975). Incorporar modelos de producción científica para comprender el registro arqueológico, implica una fusión entre el pasado y el presente; entendiendo que en cada uno se encuentra un abanico de posibilidades, entre los cuales se encierra el significado. En cada oportunidad que interpretamos el pasado, debemos tener en cuenta que lo hacemos desde el presente, con su carga de ideologías, relaciones de autoridad y poder. $\mathrm{Y}$ a su vez, con el estigma, de conocer la existencia de una multiplicidad de saberes, como los de los pueblos originarios, de las relaciones de género, que nuestro poder-saber occidental ha ocultado sistemáticamente. De la misma 
forma, cada significado desentrañado del pasado actuará en nuestro presente, dislocando, transformando y cuestionando todas nuestras estructuras pre-establecidas.

En este sentido, emplear una fusión de horizontes (entre el pasado y el presente), conlleva dejar de lado la racionalidad absoluta utilizada por una epistemología neopositivista. Esta emplea una razón indolente (Santos, 2006) que se considera única, exclusiva y que no explora la diversidad epistemológica inagotable. Este tipo de razón contrae el horizonte del presente porque deja por fuera mucha realidad, mucha experiencia, transformándola en invisible. La racionalidad neopositivista es también una razón metonímica (Santos, 2006) ya que conserva la idea que hay una escala dominante en las cosas, apuesta al universalismo; donde toda idea o entidad es válida independientemente del contexto en el que ocurre.

Por el contrario, debemos ser conscientes que toda interpretación en arqueología, responde a nuestra inserción dentro de la tradición de la disciplina: de allí nacen todos nuestros prejuicios e hipótesis. Gadamer sinte-tiza esta reflexión al marcar: "El comprender debe pensarse menos como una acción de la subjetividad que como un desplazarse uno mismo hacia un acontecer de la tradición, en que el pasado y el presente se hallan en continua mediación". (Gadamer, 1975: 360)

Únicamente interpelando "nuestro estar" en la tradición, el quehacer histórico de la arqueología y su función social, podremos dar cuenta de una multiplicidad de significados del objeto arqueológico que permanecen ocultos.

\section{Conclusión}

A lo largo de este trabajo hemos intentado demostrar porque la arqueología debe incorporarse defini-tivamente al campo de las ciencias sociales. Una de las razones, es la dificultad de aplicar el método hipotético deductivo en una disciplina que estudia las acciones sociales del pasado, para lo cual se nutre de elementos teóricos que utiliza en todos los pasos de la investigación y para quien la experiencia no basta para explicarlo todo. Otro motivo lo encontramos al establecer que la Arqueología se enriquece al abastecerse de horizontes de subjetividad e interpretación que permiten alcanzar el sentido de las acciones del pasado, robusteciendo sus hipótesis y permitiendo el diálogo entre pasado y presente. Finalmente, encontramos en las semejanzas entre el registro arqueológico y el texto, un argumento para situarnos frente a él como hermeneutas. Es decir, como actores que, aún con sus prejuicios, se hallan dispuestos a interpretar al Otro, aunque éste se halle distante, en el pasado. ${ }^{\phi 1}$ 


\section{BIBLIOGRAFIA}

ACUTO, F. (2007). Fragmentación vs integración communal: Repensando el Período Tardío en el Noroeste Argentino, Estudios Atacameños 34, 71-95.

BINFORD, L. (1981). Middle-range research and the role of actualistic studies. New York: Bones, pp. 21-30.

(1988). En busca del pasado. Barcelona: Crítica.

CARBONELLI, J.P (2011). La fuente escrita, espacio de confrontación, La Zaranda de ideas, 6: 9-25.

Argentina. Ms

y L. GAMARRA (2011). La construcción del concepto cultura en la Arqueología

EBERT, J. y T. KOHLER (1988). The theorical basis of archaeological predictive modeling and a consideration of appropiate data-collection methods. En: Quantifying the present and predicting the past: theory, method and application of archaeological predictive modeling. Ed. W.J.Judge y L. Sebastian, pp. 97-123. Denver, Colorado: Bureau of Land Management.

FEYERABEND, P. (1981). Contra el método. España: Editorial Ariel.

GADAMER, H.G. (1975). Truth and Method. London: Sheed and Ward.

GARCIA, J. F. (2004). Acción humana y Ley; crítica a la unidad metodológica de las ciencias. En: Popper y las Ciencias Sociales, Ed. F.G.Schuster, 440 pp. Editores de America Latina: Buenos Aires.

GUIDDENS, A. (1987). Social Theory and Modern Sociology. Cambridge: Polity Press.

HARALD J. y B. OLSEN (1992). Hermeneutics and archaeology: on the philosophy of contextual archaeology, American Antiquity 57(3): 419-436.

HIDALGO, C. (2004). La lógica de la situacion. En: Popper y las Ciencias Sociales, Ed. F.G.Schuster, 440 pp. Editores de America Latina: Buenos Aires.

HODDER, I. (1986). Reading the past. Cambridge: Cambridge University Press. 44: $11-26$.

(1987). La Arqueología en la era post-moderna. Madrid: Trabajos de Prehistoria

HOYOS VAZQUEZ, G. (2004). ¿Epistemología sin sujeto cognoscente?. En: Popper y las Ciencias Sociales, Ed. F.G.Schuster, 440 pp. Editores de America Latina: Buenos Aires.

LOREZ ARNAIZ, M.R (2004). La concepción popperiana de la racionalidad. En: Popper y las Ciencias Sociales, Ed. F.G. Schuster, 440 pp. Editores de America Latina: Buenos Aires.

NIELSEN, A. (2001). Evolución social en la quebrada de Humahuaca (AD 700-1536). En: Historia prehispánica argentina, Eds. E. Berberián y A. Nielsen, vol. 1 pp. 171-264. Córdoba: Editorial Brujas

POPPER, K. (1977). Búsqueda sin término. Madrid: Tecnos. 
(1981a) La miseria del historicismo. Madrid: Alianza.

(1981b). La sociedad abierta y sus enemigos. Bs. As: Paidós.

PREUCEL, R.W and I. HODDER (1996). Contemporary Archaeology in Theory. A Reader. Blackwell: Cambridge.

RICOEUR, P. (2008 [1985]). Hermeneútica y acción. De la Hermeneútica del Texto a la Hermeneútica de la Acción. Bs.As: Prometeo Libros.

SANTOS, B. (2006). Renovar la teoría crítica y reiventar la emancipación social. CLACSO: Buenos Aires.

TARRAGO, M. (2000). "Chakras y pukara. Desarrollos sociales tardíos". En: Los pueblos originarios y la conquista. Nueva historia argentina, Ed. M. Tarragó, vol. 1, pp. 257-300. Editorial Sudamericana: Buenos Aires.

TRIGGER, B.C. (1989). Historia del Pensamiento Arqueológico. Barcelona: Crítica. $500 \mathrm{pp}$.

Juan Pablo Carbonelli es Licenciado en Ciencias Antropológicas (orientación Arqueología) y Profesor en Enseñanza Media y Superior en Ciencias Antropológicas (UBA). Becario de CONICET, en el Museo Etnográfico Juan B. Ambrosetti, UBA FFyL. Adscripto de la Cátedra Arqueología Argentina, UBA. Integrante del Proyecto Yocavil, investiga la transición cazadores-recolectores a sociedades agro-pastoriles plenas en el Valle de Santa María, Catamarca. 